\title{
The Perspectives of Medical Oncology Specialists in Screening Methods of Cancer
}

\section{Kanserde Erken Tanı ve Tarama Konularına Tıbbi Onkologların Yaklaşımları}

\author{
Ece Esin $^{1}$, Deniz Yüce², Beril Hüseyin², Saadettin Kılıçkap² \\ ${ }^{1}$ Hacettepe Üniversitesi Tıp Fakültesi Kanser Enstitüsü Medikal Onkoloji Bilimdalı, Ankara \\ ${ }^{2}$ Hacettepe Üniversitesi Tıp Fakültesi Kanser Enstitüsü Prevantif Onkoloji AD, Ankara
}

\section{ÖZET}

GíRiş ve AMAÇ: Kanserde mortalite ve morbiditenin azaltılmasının başlıca yolu tarama programları ile hastalık gelişiminin mümkün olduğunca erken tanı konularak yakalanması ve uygun müdahalelerin gerçekleştirilmesidir. Bu konuda topluma yol gösterici olması gereken kişilerin başında onkoloji alanında uzmanlaşmış hekimler gelmektedir. Bu çalışmanın amacı ülkemizdeki tıbbi onkologların erken tanı ve tarama konularındaki uygulama alışkanlıklarının değerlendirilmesidir.

YÖNTEM ve GEREÇLER: Tıbbi onkologların erken tanı ve tarama konularındaki uygulama alışkanlıkları 37 soruluk bir anket ile değerlendirildi.

BULGULAR: Anketi 94 medikal onkoloji uzmanı cevapladı. Cevaplayanların \%60'1 üniversitede, \%37'si devlet hastanesinde çalışıyordu. Katılımcıların \%11'i profesör, \%8'i doçent, \%9'u yardımcı doçent, \%42'si uzman ve \%29'u yan dal araştırma görevlisi idi. Mesleki deneyimler incelendiğinde \%48'i 3-10 yıl arasında, \%37'si 1-3 yıl arasında, \%12'si 10yıl üzerinde idi. Katılımcıların yaklaşık yarısı akciğer kanseri için tarama yapılması gerektiğini düşündüklerini bildirmişler, ancak \%22'si rutin taramayı önermişlerdir. En az gaitada gizli kan incelemesinin faydalı olduğuna inanıldığı $(\% 55,1)$ ve en az rektal muayenenin hasta ve sağlıklı bireylere önerildiği $(\% 45,7)$ belirlenmiştir. Mamografinin ise faydalı olduğuna en çok inanılan $(\% 96,7)$ ve önerilen $(\% 98,9)$ yöntem olduğu görülmüștür.

TARTIŞMA ve SONUÇ: Onkoloji ile ilgilenen sağlık profesyonellerinin kanserde erken tanı ve tarama yöntemleri hakkındaki algı ve uygulama alışkanlıklarının genelde benzer olduğu, ancak kanser taraması için yararlı olduklarını düşündükleri bu yöntemleri günlük pratikte hastalarına daha az önerdikleri dikkati çekmiștir. Bu konunun sağlık hizmetlerinin bir parçası olduğu unutulmamalıdır.

Anahtar Kelimeler: Tarama, kanserde erken tanı, mamografi, kolonoskopi, onkolog

\begin{abstract}
INTRODUCTION: One the main methods of reducing mortality and morbidity in cancer is screening programs and the early detection of disease and therefore increasing the awareness of appropriate interventions. In this regard, specialists in the field of oncology are at the forefront of those who should guide the population. The aim of this study is to evaluate the practice habits of medical oncologist in screening programs. METHODS: The practice habits of medical oncologists regarding early diagnosis and screening of cancer was evaluated by a 37 -item questionnaire.

RESULTS: Of the medical oncologist who were sent the survey, 94 of them replied. Sixty percent of the respondents were in college and $37 \%$ were working in state hospital. Eleven percent of the participants were professors, $8 \%$ were associate professors, $9 \%$ were assistant professors, $42 \%$ were experts and $29 \%$ were fellows. When the duration of expertise was examined, $48 \%$ have 3-10 years of experience, $37 \%$ between 1-3 years, $12 \%$ over 10 years. Nearly half of the participants reported that they should offer screening for lung cancer, but $22 \%$ recommended routine screening. It was determined that occult blood analysis was useful $(55.1 \%)$ and at least rectal examination was recommended to patients and healthy subjects $(45.7 \%)$. Mammography was the most believed (96.7\%) and the recommended (98.9\%) method.

DISCUSSION and CONCLUSION: It has been noticed that the health professionals who are interested in oncology generally have similar perception and practice habits about early diagnosis and screening methods of cancer. However, they offer these methods to patients in daily practice less than they think they are useful for cancer screening. It should not be forgotten that this is part of health services.
\end{abstract}


Keywords: Screening, early diagnosis, mamography, colonoscopy, oncologist.

\section{GíRIŞ}

Tarama, Dünya Sağl1k Örgütü (DSÖ) tarafindan testler, incelemeler veya hizla uygulanabilecek diğer işlemler yoluyla olası hastalık veya kusurların belirlenmesi olarak tanımlanır(1).Kisaca tarama, herhangi bir semptom veya yakınması olmayan sağlıklı bir bireyde belirli bir hastalığın erken bulgularını araştırmak demektir. Tarama programlarının amacı hastalığın önlenmesinden ziyade hastalığa erken tanı konulmasını sağlamaktır. Kanser tarama programları bu açıdan önem taşımaktadır.

Kanser tarama programları ulusal kanser kontrol programları dahilinde yürütülmeli ve ülkelerin sosyal altyapısı, kanser özellikleri ve bütçesi dahilinde planlanmalıdır. Taramanın başarısı, tarama testlerini yapmak için yeterli sayıda personele ve daha sonra tanı, tedavi ve izlemeyi üstlenebilecek olanakların bulunmasina bağlıdır. Tütünle küresel mücadele ve obeziteye karşı alınan önlemler gibi birincil koruma kapsamındaki mücadeleler dışındaki erken tanı ve tarama programlarını da uygulanmas1 DSÖ tarafindan önerilmektedir(1). Kanser tarama programlarının uygulama oranları arttıkça ileri evrede tan1 alan kanser olgular1 ile meme, serviks, kolorektal kanser gibi önlenebilen ve erken tanı konulabilen malignansilere bağl1 ölümlerin azalacağ öngörülmektedir.

Ulusal toplum tabanlı kanser taramaları Aile Sağlığı Merkezleri (ASM) ve Toplum Sağlığı Merkezleri (TSM) bünyesindeki Kanser Erken Teşhis, Tarama ve Eğitim Merkezleri (KETEM) tarafindan yürütülmektedir (2).Toplumun kanser hakkında bilgilendirilmesi, bilinçlendirilmesi ve ulusal kanser tarama programlarına yöneltilmesi konusunda yol gösterici olmas1 gereken kişilerin başında onkoloji alanında uzmanlaşmış hekimler gelmektedir. Onkoloji uzmanlar1, kanser tanis1 konduktan sonra hastalığı durdurmak veya yavaşlatmak konusunda oldukça fazla yol almış durumdadır. Kanserin tarama programları ile önlenmesinde ise önemli yükümlülük ve görevleri olduğu bilinmektedir. Ancak günlük pratikte yoğun çalışma koşulları varlığında tıbbi onkologlar tedavi sürecine ek olarak esas hedef olan prevansiyona yeterince vakit ayıramıyor olabilirler. Ya da ulusal kanser tarama programı dahilinde yapılan mamografi, kolonoskopi, servikal smear testinin uygulanmasının gerekliliğine ve güvenilirliğine dair onkoloji hekimlerinin inanc1 birbirinden farklı olabilir $(3,4)$. Bu farklılıklar ise tarama programlarına yönlendirilen hasta oranlarını belirlemekte ve önem taşımaktadır(5,6). Benzer şekilde kanser tedavisindeki gelişmeler ile elde edilen artmış kür oranı ve daha uzayan sağkalımlar ile kanserden sağkalanlar için ikincil koruma daha da önem kazanmaktadır(7, 8). Daha önceki analizlerde özellikle bu hassas popülasyonda kanser taramasının yetersiz olduğuna dair sonuçlar mevcuttur $(9,10)$.

Çalışmamızdaki

amacimiz, ülkemizde kanser tedavi sürecinde aktif rol oynayan tıbbi onkologların erken tanı ve tarama konularındaki uygulama alışkanlıklarının değerlendirilmesidir.

\section{MATERYAL ve METOT}

Çalışmamızda tıbbi onkologların erken tanı ve tarama konularındaki uygulama alışkanlıkları, 2012 y1lında gerçekleştirilen bir anket çalışması ile değerlendirilmiştir. Ulusal bazlı çalışmamızda Türkiye'de görev yapan Tıbbi Onkologlar ile elektronik posta ile temas kurulmuş ve anket formu gönderilmiştir. Anket formu tıbbi onkoloji uzmanlarının kanserde erken tanı ve tarama yöntemleri hakkındaki düşünce ve uygulama alışkanlıklarını değerlendiren 37 soru içermektedir. Çalışma için 110 hekime davet gönderilmiş ve anketi 94 medikal onkoloji uzmanı cevaplamış, yanıt oran $1 \% 85,5$ olarak tespit edilmiştir.

Verilerin analizi için SPSS $^{\circledR}$ v.20 istatistik programından faydalanılmıştır. Deskriptif istatistikler kategorik değişkenler için ki-kare ve sürekli değişkenler için MannWhitney testi ile yapılmıştır.

$\mathrm{P}<0,05$ değeri istatiksel olarak anlamlı kabul edilmiştir. 
Tablo 1: Katılımcıların Özellikleri

Katılımcıların Özellikleri (n=94)

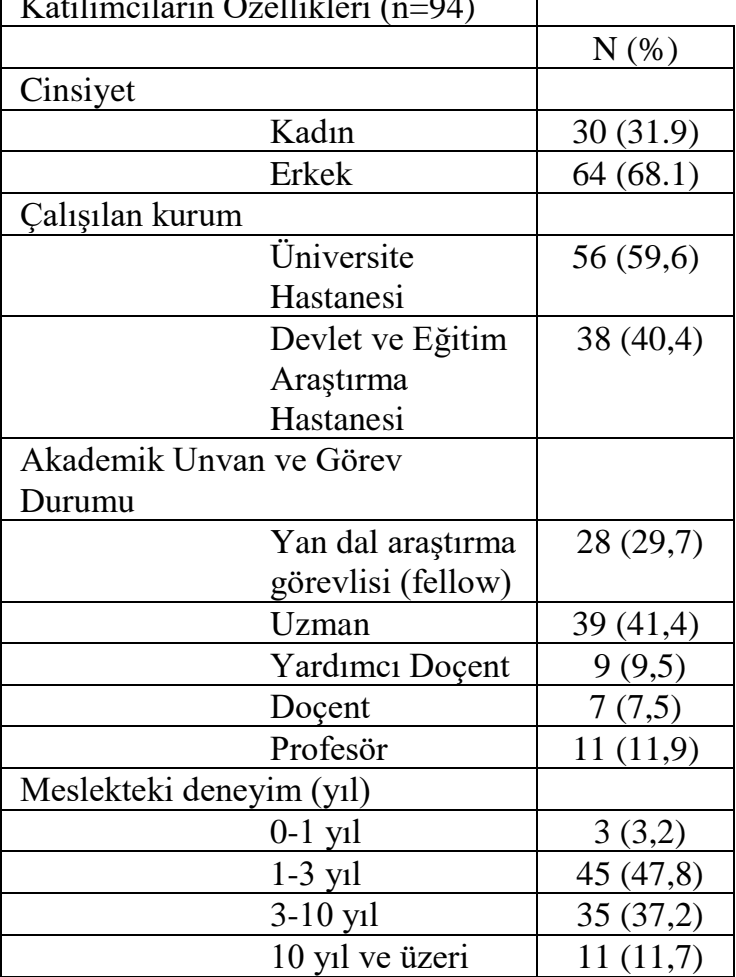

\section{SONUÇLAR}

Anketi 94 medikal onkoloji uzmanı cevaplamıştır. Ankete cevap veren medikal onkologlardan \%68,1'i erkek; \%31,9'u kadındı. Anketi cevaplayan kadın medikal onkologlar ile erkek medikal onkologlar arasında en sik tercih edilen tarama yöntemi açısından (mamografi) anlamlı fark saptanmadi.

Tablo 2. Erken tanı ve tarama yöntemleri hakkındaki algı ve uygulama durumları

\begin{tabular}{|c|c|c|c|c|c|c|c|c|c|c|c|c|c|c|c|c|}
\hline & \multicolumn{4}{|c|}{$\begin{array}{c}\text { Erken tanıda yararlı } \\
\text { olduğuna inanıyor } \\
\text { mu? }\end{array}$} & \multicolumn{4}{|c|}{$\begin{array}{c}\text { Hasta ve sağlıklı } \\
\text { bireylere öneriyor } \\
\text { mu? }\end{array}$} & \multicolumn{8}{|c|}{$\begin{array}{l}\text { Bir aylık sürede gördüğ̈ü hasta ve sağlıklı } \\
\text { bireylerden yüzde kaçına öneriyor? }\end{array}$} \\
\hline & \multicolumn{2}{|c|}{ Hayır } & \multicolumn{2}{|c|}{ Evet } & \multicolumn{2}{|c|}{ Hayır } & \multicolumn{2}{|c|}{ Evet } & \multicolumn{2}{|c|}{$<\% 10$} & \multicolumn{2}{|c|}{$\% 10-30$} & \multicolumn{2}{|c|}{$\% 31-50$} & \multicolumn{2}{|c|}{$>\% 50$} \\
\hline & $\mathrm{n}$ & $\%$ & $\mathrm{n}$ & $\%$ & $\mathrm{n}$ & $\%$ & $\mathrm{n}$ & $\%$ & $\mathrm{n}$ & $\%$ & $\mathrm{n}$ & $\%$ & $\mathrm{n}$ & $\%$ & $\mathrm{n}$ & $\%$ \\
\hline $\begin{array}{l}\text { Kendi kendine } \\
\text { periyodik meme } \\
\text { muayenesi }\end{array}$ & 15 & 16,0 & 79 & 84,0 & 5 & 5,3 & 89 & 94,7 & 8 & 9,0 & 23 & 25,8 & 23 & 25,8 & 35 & 39,3 \\
\hline $\begin{array}{l}\text { Hekim tarafindan } \\
\text { yapılan meme } \\
\text { muayenesi }\end{array}$ & 14 & 14,8 & 79 & 84,0 & 12 & 12,8 & 83 & 88,3 & 14 & 17,1 & 22 & 26,8 & 17 & 20,7 & 29 & 35,4 \\
\hline Mamografi & 3 & 3,2 & 89 & 94,7 & 1 & 1,1 & 93 & 98,9 & 3 & 3,2 & 18 & 19,4 & 20 & 21,5 & 52 & 55,9 \\
\hline Rektal muayene & 30 & 31,9 & 59 & 62,8 & 50 & 53,1 & 42 & 44,7 & 33 & 51,6 & 15 & 23,4 & 6 & 9,4 & 10 & 15,6 \\
\hline Gaitada gizli kan & 40 & 42,6 & 49 & 52,1 & 44 & 46,8 & 49 & 52,1 & 23 & 37,7 & 19 & 31,1 & 8 & 13,1 & 11 & 18,0 \\
\hline Rektosigmoidoskopi & 7 & 7,4 & 82 & 87,2 & 9 & 9,6 & 85 & 90,4 & 18 & 19,8 & 34 & 37,4 & 10 & 11,0 & 29 & 31,9 \\
\hline PSA & 19 & 20,2 & 69 & 73,4 & 23 & 24,5 & 71 & 75,5 & 15 & 19,0 & 19 & 24,1 & 18 & 22,8 & 27 & 34,2 \\
\hline PAP smear & 0 & 0,0 & 90 & 95,7 & 3 & 3,2 & 90 & 95,7 & 8 & 8,7 & 21 & 22,8 & 14 & 15,2 & 49 & 53,3 \\
\hline HPV & 28 & 29,8 & 58 & 61,7 & 61 & 64,9 & 32 & 34,0 & 42 & 73,7 & 7 & 12,3 & 0 & 0,0 & 8 & 14,0 \\
\hline
\end{tabular}




\section{Çıkar Çatışması: Yok}

\section{REFERANSLAR}

1. World Health Organization. Screening for various cancers: WHO position paper on mammography screening. In; 2017.

2. Türkiye Halk Sağlığı Kurumu Kanser Savaş Daire Başkanlığı. Kanser Taramaları Kısa Rapor 2014. In; 2014.

3. Steinbrook R. Guidance for guidelines. N Engl J Med 2007; 356: 331-3.

4. Gerber AS, Patashnik EM, Doherty D, Dowling C. A national survey reveals public skepticism about research-based treatment guidelines. Health Aff (Millwood) 2010; 29: 1882-4.

5. Hawley ST, Earp JA, O'Malley M, Ricketts TC. The role of physician recommendation in women's mammography use: is it a 2-stage process? Med Care 2000; 38: 392-403.

6. Nichols C, Holt CL, Shipp M, Eloubeidi M, Fouad MN, Britt K. Physician knowledge, perceptions of barriers, and patient colorectal cancer screening practices. Am J Med Qual 2009; 24: 116-22.

7. Siegel R, DeSantis C, Virgo K, Stein K, Mariotto A, Smith T, et al. Cancer treatment and survivorship statistics, 2012. CA Cancer J Clin 2012; 62: 220-41.

8. Inskip PD, Curtis RE. New malignancies following childhood cancer in the United States, 1973-2002. Int J Cancer 2007; 121: 2233-40.

9. Cho J, Guallar E, Hsu YJ, Shin DW, Lee WC. A comparison of cancer screening practices in cancer survivors and in the general population: the Korean national health and nutrition examination survey (KNHANES) 2001-2007. Cancer Causes Control 2010; 21: 2203-12.

10. Grunfeld E, Moineddin R, Gunraj N, Del Giudice ME, Hodgson DC, Kwon JS, et al. Cancer screening practices of cancer survivors: population-based, longitudinal study. Can Fam Physician 2012; 58: 980-6.

11. Ashford A, Gemson D, Sheinfeld Gorin SN, Bloch S, Lantigua R, Ahsan H, et al. Cancer screening and prevention practices of inner-city physicians. American journal of preventive medicine 2000; 19: 59-62.

12. LoGerfo J, Corral JE, Arnold LD, Argueta EE, Ganju A, Barnoya J. Clinical Preventive Services in Guatemala: A Cross-Sectional Survey of Internal Medicine Physicians. PLoS ONE 2012; 7: e48640. 